\title{
Motivational Orientations of High-Achieving Students as Mediators of a Positive Percep- tion of a High-Achieving Classmate: Results from a Cross-national Study
}

\author{
Hyerim Oh${ }^{1}$, Maria del Mar Badia Martín'², Sheyla Blumen ${ }^{3}$, Julie Maakrunn ${ }^{4}$ Quoc An-Thu Nguyena ${ }^{1}$, Niamh Stack ${ }^{5}$, Marga- \\ ret Sutherland ${ }^{5}$, Catherine Wormald ${ }^{6}$ and Albert Ziegler ${ }^{*}$ \\ ${ }^{1}$ Educational Psychology and Research on Excellence, University of Erlangen-Nuremberg, Nuremberg (Germany). \\ ${ }^{2}$ Department of Basic, Development and Educational Psychology, University Autonomous of Barcelona, Barcelona (Spain). \\ ${ }^{3}$ Department of Psychology, Pontificia Universidad Católica del Perú, Lima (Peru). \\ ${ }_{4}$ School of Education, University of Notre Dame, Sydney (Australia). \\ ${ }^{5}$ School of Psychology/School of Education, University of Glasgow (United Kingdom). \\ ${ }^{6}$ School of Education, University of Wollongong, Wollongong (Australia).
}

Título: Orientaciones motivacionales de los estudiantes de alto rendimiento como mediadoras de una percepción positiva por parte de sus compañeros: resultados de un estudio transnacional.

Resumen: El propósito de este estudio es explorar si las motivaciones de alto logro influencian las percepciones de los alumnos sobre un futuro compañero de clase ficticio que se caracteriza por tener un alto rendimiento; y si es así de qué modo ocurre. La muestra final consistió en 396 alumnos de alto rendimiento que fueron seleccionados de un total de 1794 alumnos de séptimo y decimo grado de cinco países: Australia, Perú, Corea del sur, España y Vietnam. Se llevaron a cabo una serie de modelos de regresión por pasos sucesivos para probar la hipótesis de que las percepciones positivas sobre un compañero de alto rendimiento podrían estar mediadas por el enfoque motivacional, pero no por la orientación a la evitación del trabajo. La hipótesis fue confirmada en su generalidad. Las metas orientadas al manejo del aprendizaje y las orientadas al alto rendimiento predijeron percepciones positivas de la habilidad intelectual, cualidades sociales y popularidad entre los compañeros del alumno de alto rendimiento, mientras que las metas de evitación del trabajo no obtuvieron correlaciones significativas. Sin embargo, se dieron algunas excepciones esporádicas entre los participantes de Vietnam, Corea del sur y Perú.

Palabras clave: Orientación motivacional, alto rendimiento, diferencias entre países.

\section{Introduction}

There is ample evidence in the literature that gifted and high-achieving students are at a higher risk of facing various social problems like social isolation, social rejection, being stereotyped or negatively labelled, for example, as a nerd or a geek (e.g., Fiedler, Lange, \& Winebrenner, 1993; Händel, Duan, Sutherland, \& Ziegler, 2014; Peterson, 2009; Piechowski, 1997). Person (2010) showed with both quantitative and qualitative data that for many high ability students schools are "hostile environments". By way of illustration, some of the quotes provided in Person's study from high ability students include "I usually knew more than most others and was bullied for it"; "being a deviant, it was easy to become an outcast"; and "I was harassed and bullied for the most part during the entire duration of school" (p. 551).

This research suggests that it may not be desirable for a highly able student to live up to his or her potential and become a high achieving student. However, a crucial role

* Dirección para correspondencia [Correspondence address]

Albert Ziegler .Friedrich-Alexander-Universität Erlangen-Nürnberg. Lehrstuhl für Pädagogische Psychologie und Exzellenzforschung. Regensburger Straße 160. 90478 Nürnberg. Raum St.Paul 01.511 (Germany). E-mail: Albert.Ziegler@fau.de
Abstract: The purpose of this study was to explore whether and in what ways high-achieving school students' motivational orientations influence their perceptions of a fictitious future high-achieving classmate. The final sample consisted of the 396 highest achieving students out of a sample from 1794 seventh and tenth graders from five countries: Australia, Peru, South Korea, Spain, and Vietnam. A series of stepwise regression models were used to test the hypothesis that positive perceptions of a highachieving classmate might be mediated by an approach motivation, but not by an avoidance motivational orientation. The hypothesis was generally confirmed. Learning goal orientation and performance approach motivation predicted positive perceptions of a high-achieving classmate's intellectual ability, social qualities and popularity among peers, whereas a performance avoidance orientation was usually uncorrelated. However, sporadic exceptions have been found among the participants from Vietnam, South Korea, and Peru.

Key words: Motivational orientation, high-achievers, country differences.

might be played by peers. They serve various functions in the development of the gifted, in particular regarding competition, support, motivation, and role modeling (Lee, 2002). Given the fact that peer models can be extremely important at all stages of academia to high ability students and as choosing the wrong role models can be a contributing factor to underachievement (Baker; Bridger, \& Evans, 1998/2011; Händel, Vialle, \& Ziegler, 2013; Shin, Levy, \& London, 2016; Stopper, 2000) this raises the question of how high achieving students perceive other high-achieving students. Indeed, it can be argued that high-achieving students benefit most from classroom interactions with students of similar achievement levels (Fiedler, et al., 1993; Peterson, 2009). However, various factors might moderate the willingness of high-achieving students to adopt other highachieving students as role models. We will investigate one such factor in this deliberation: motivational orientations.

In achievement contexts motivational orientations can direct personal behaviors toward the attainment of achievement goals (Brendl, Markman, \& Messner, 2003; Dweck \& Leggett, 1988; Harackiewicz \& Elliot, 1993; Markman \& Brendl, 2000). When pursuing mastery goals individuals adopt a learning goal orientation, and thus a student's purpose is to approach the goal of learning through mastering challenges. When pursuing performance approach goals, a 
student strives to demonstrate task competence and reveal high performance. The learning goal orientation and the performance approach orientation are usually considered as different types of an approach orientation (but see Elliot, 1999, for an alternative point of view). Performance avoidance orientations are characterized as avoidance goals, because the student focuses on avoiding situations that reveal incompetence. Thus, individuals who subscribe to such an orientation are thought to be driven by the prevention of possible failure.

Some evidence already exists that an approach orientation might be an especially important factor in the perception of high-achieving students. For example, Lockwood \& Kunda (1997) found that high-achieving role models can only be effective when the observer believes they can also attain comparable performance levels. Similarly, research evidence suggests that role models have more positive effects when they have acquired their skills through learning and not just because they are considered as gifted (Bagès, \& Martinot, 2011).

These findings seem to be consistent with other studies. Goal-related environments and activities are generally preferred to those that are irrelevant to a goal (Brendl et al., 2003; Ferguson \& Bargh, 2004; Read \& van Leeuwen, 1998). It therefore seems reasonable to suggest that people's attitudes toward their environment (people, objects) rely on the degree to which the environment can be useful for attaining a goal. Based on this functional perspective, the individual pursuit of a goal causes people to perceive useful stimuli as more positive or less negative. Those who are pursuing a goal automatically evaluate relevant stimuli as more positive in comparison with those are not striving to attain a goal. For example, studies revealed that students whose performance goal orientation has been stimulated exhibited a preference for information related to their performance goals (Ferguson \& Bargh, 2004). However, there is also evidence for a devaluation effect. For example, in some studies (e.g., Brendl et al., 2003) it has been reliably demonstrated that goal-unrelated stimuli in one's environment are devalued when the person was pursuing a goal.

\section{Aim of the present study}

The present study is an explorative study in which we investigate how favorably high-achieving students perceive a (fictitious) high-achieving future classmate. Our sample consists of adolescent students in the top $20 \%$ of school records. Indeed, excellence in schools is typically defined in terms of grades and performance because academic outcome is easily measured.

In the competition context of schools, high-achievers have already experienced academic success on prior exams. Their past achievement histories engender them to set highperformance expectations for an upcoming exam. The experience of academic successes usually leads high-achievers to reflect on, and endorse, approach goals, whereas low per- forming students' achievement orientations are not characteristically oriented towards competence (Brophy, 2005; Harackiewicz \& Elliot, 1993). Taking into account that approach goals lead to positive evaluations of goal-related stimuli (Brendl et al., 2003; Ferguson \& Bargh, 2004; Markman \& Brendl, 2000; Read \& van Leeuwen, 1998) in this study we propose that approach goals will lead to more positive evaluations of high-achievers attributes. Thus, the first hypothesis of this study is: When high-achieving students endorse an approach motivation (either a learning goal orientation or a performance approach orientation) they will evaluate characteristics of a high-achieving student more positively.

In contrast, we assume that students with a performance avoidance orientation devalue information related to a highachieving peer (cf. Brendl et al., 2003). Indeed, students with high-achievements particularly avoid revealing their underperformance relative to their higher performing classmates (e.g., Neumeister \& Finch, 2006). Thus, students with avoidance motivational orientation may not be interested in the characteristics of the successful student. The second hypothesis in this study therefore is: A performance avoidance orientation of high-achieving students will not be related to evaluations of attributes of high-achieving peers in school.

Our hypotheses are not related to a specific culture. However, there is evidence that motivational orientations can have different effects among students of different cultures (Salili, Chiu, \& Lai, 2001; Tao \& Hong, 2000). Thus, as an exploratory study the current research also focuses on differences in country cultures ranging from those traditionally perceived as highly individualistic to highly collective cultures (Hofstede, 2001; Triandis, 1995): Australia, Spain, Peru, South Korea, and Vietnam.

\section{Method}

\section{Participants}

The sample consists of 1794 seventh and tenth graders. In particular, 479 Vietnamese (51.4\% female), 359 South Korean (47.6\% female), 168 Australian (53.0\% female), 399 Peruvian (48.6\% female), and 389 Spanish $(45.0 \%$ female) were asked for their latest school grades in three major compulsory subjects - mathematics, science and language. The final sample of 396 students were among the $20 \%$ highest achieving students according to their GPA in their national sample. The average age of the participants was 13.42 years $(S D=1.52)$ with a range from 11 to 16 years. There is no significant difference in age between country groups $(p=$ .548). The numbers of the participants and gender ratios of the final sample in each country are presented in Table 1.

\section{Measurement}

Questionnaires in paper-and pencil format were administered to the students during their regularly scheduled classes. 
Trained local research assistants administered the questionnaires. The English questionnaire was translated into each local language according to usual conventions (Behling \& Law, 2000; Smith, 2004) including back translations. All responses were given on a Likert scale ranging from 1 (strongly disagree) to 6 (strongly agree).

\section{Perceptions of high-achiever attributes}

Students were asked to imagine two fictitious new classmates were joining their class. The order of the questionnaire was gender balanced. Half of the participants started with a fictitious male classmate, the other half with a fictitious female classmate. The following instructions were provided to participants:

For the following statements, we want to know what expectations you have, when a new girl (boy) comes into your class. The only thing you know about her (him) is that she (he) was the best student in her (his) previous school. Read each statement and colour the circle that best describes your feelings about the statement.

Similar formats have been widely used in studies of impression formation (Heise, 2010; Rossi \& Nock, 1982). For the male and female fictitious high-achieving student participants were asked to indicate their expectations of the new classmate in relation to a list of fourteen pre-defined characteristics (see Händel et al., 2013). The items were to be answered on a 6-point Likert scale. Similarly to Händel et al. (2014) the items were categorized into three areas: intellectual abilities (e.g. ".... is very intelligent", “... has many good ideas"), popularity (e.g. " ... will be popular in the class", “... is carefree and cool") and social qualities (e.g. "... has a sense of humor", “...communicates well”). Cronbach's $\alpha$ for the six scales were .77 (intellectual abilities male student), .75 (intellectual abilities female student), .59 (popularity male student), .57 (popularity female student), .83 (social qualities male student), and .81 (social qualities female student).

\section{Motivational orientations}

Participants' achievement motivations were measured using a scale from Ziegler, Dresel, and Stoeger, (2008). The items capture three motivational orientations: learning goal orientation, performance approach orientation, and performance avoidance orientation. Learning goal orientation was measured with six items (e.g., In school I want to improve my skills; $\alpha=.80$ ). The scale for performance avoidance goal comprises nine items (e.g. I do not want my parents to reproach me because I am bad in school; $\alpha=.59$ ). Performance approach goal was assessed with nine items (e.g., I want my classmates to notice how good I am; $\alpha=.78$ ).

\section{Results}

\section{Descriptive Analysis}

In a first step we conducted a series of three planned $\mathrm{T}$ tests between the corresponding scales of attributes of a fictitious male and female student in each country. Error level was set at $p=.05$ and no $\alpha$-adjustment was made. However, no significant gender differences were found. Thus, in order to minimize Type 1 error we combined the corresponding male and female target scales of intellectual abilities, social qualities and popularity to three new scales termed as follows INT, SOC, and POP.

Means $(M)$ and standard deviations $(S D)$ for each scale are shown in Table 1 . The results indicate that overall high achieving participants hold positive expectations about the new high-achieving classmate regarding INT, SOC, and POP. All ratings were above the scale mean of 3.5 and most above 4 (agreement). Exceptions were only found for the performance avoidance orientations in Vietnam $(M=3.77$, $S D=0.67)$, South Korea $(M=3.94, S D=0.65)$, and Spain $(M=3.74, S D=0.95)$.

Table 1. Descriptive statistics $(N=396)$.

\begin{tabular}{lccccc}
\hline & Vietnam & South Korea & Australia & Peru & Spain \\
\cline { 2 - 5 } & $M(S D)$ & $M(S D)$ & $M(S D)$ & $M(S D)$ & $M(S D)$ \\
\hline Age (years) & $13.27(1.49)$ & $13.53(1.54)$ & $13.73(1.54)$ & $13.73(1.54)$ & $13.43(1.52)$ \\
$N \quad$ & 111 & 76 & 37 & 83 & 89 \\
$\quad$ Female (\%) & $59 \%$ & $41 \%$ & $43 \%$ & $49 \%$ & $51 \%$ \\
Perception of High-Achievers Attributes & & & & \\
$\quad$ Intellectual ability & $4.52(.81)$ & $4.57(.75)$ & $4.94(.72)$ & $4.62(.69)$ & $5.08(.84)$ \\
$\quad$ Social qualities & $4.15(.81)$ & $3.93(.78)$ & $4.34(.78)$ & $4.60(.65)$ & $5.38(.69)$ \\
$\quad$ Popularity & $3.85(.48)$ & $3.97(.60)$ & $4.18(.45)$ & $4.44(.57)$ & $4.15(.57)$ \\
Motivational Orientation & & & & & $5.61(.52)$ \\
$\quad$ Learning goal & $4.84(.76)$ & $4.97(.74)$ & $5.64(.46)$ & $4.84(.62)$ & $4.83(.71)$ \\
$\quad$ Performance approach & $4.44(.75)$ & $4.61(.81)$ & $4.39(.80)$ & $4.63(.59)$ & $3.75(.95)$ \\
$\quad$ Performance avoidance & $3.77(.67)$ & $3.94(.65)$ & $4.01(.56)$ & $4.33(.50)$ & $3.74(.95)$
\end{tabular}

\section{Correlational Analyses}

In the first hypothesis we stated that high-achieving students who endorse an approach motivation (either a learning goal orientation or a performance approach orientation) would evaluate characteristics of a high-achieving student more positively. To examine this hypothesis correlation analyses were conducted (see Table 2). For the participants 
across the country groups the Pearson correlations were positive except for a non-significant negative correlation between popularity and learning goal orientation in Peru. All in all, 19 of the predicted 30 correlations proved to be significant $(p<0.05)$ and thus mainly confirmed the anticipated relationships. However, substantial country differences were found. In the two Asian countries, Korea and Vietnam, the expected correlations turned out, with the exception of a learning goal orientation with popularity, to be significant. In neither sample in Australia nor in Peru did a learning goal orientation correlate with any of the measured attributes of the fictitious high-achieving student (i.e., intellectual abilities, expected social attributes, and popularity). In contrast, if we include marginally significant correlations $(p<.10)$ a learning goal orientation correlated in Spain with all the measured attributes. However, in Spain a performance approach orientation correlated only with expected intellectual abilities and was marginally significant with the expected social qualities of the fictitious high-achieving student. A performance approach orientation correlated in Australia as well as in Peru with all the three measured attributes.

Table 2. Correlations among all variables.

\begin{tabular}{|c|c|c|c|c|c|}
\hline Vietnam & INT & SOC & POP & Mastery & PAP-goals \\
\hline SOC & $.52^{* *}$ & & & & \\
\hline POP & $.80^{* *}$ & $.41 * *$ & & & \\
\hline Learning Goal & $.72^{* *}$ & $.44^{* *}$ & $.56^{* *}$ & & \\
\hline Performance approach & $.57^{* *}$ & $.34^{* *}$ & $.46 * *$ & $.56^{* *}$ & \\
\hline Performance avoidance & $.24^{* *}$ & $.22^{* *}$ & $.28^{* *}$ & .14 & $.32^{* *}$ \\
\hline Korea & INT & SOC & POP & Mastery & PAP-goals \\
\hline SOC & $.42^{* *}$ & & & & \\
\hline POP & $.82^{* *}$ & $.28^{*}$ & & & \\
\hline Learning Goal & $.23^{*}$ & $.25^{*}$ & .05 & & \\
\hline Performance approach & $.46^{* *}$ & $.20^{*}$ & $.36^{* *}$ & $.36^{* *}$ & \\
\hline Performance avoidance & $.23^{*}$ & -.10 & $.29 *$ & .05 & $.36^{* *}$ \\
\hline Australia & INT & SOC & POP & Mastery & PAP-goals \\
\hline SOC & $.57^{* *}$ & & & & \\
\hline POP & $.64 * *$ & $.29 *$ & & & \\
\hline Learning Goal & .11 & .21 & .05 & & \\
\hline Performance approach & $.33^{*}$ & .27 & $.28^{*}$ & $.36^{*}$ & \\
\hline Performance avoidance & .26 & $.38^{*}$ & .12 & .28 & $.66^{* *}$ \\
\hline Peru & INT & SOC & POP & Mastery & PAP-goals \\
\hline$\overline{\mathrm{SOC}}$ & $.63^{* *}$ & & & & \\
\hline POP & $.71^{* *}$ & $.40 * *$ & & & \\
\hline Learning Goal & .10 & .16 & -.08 & & \\
\hline Performance approach & $.27^{* *}$ & $.26^{* *}$ & $.26^{* *}$ & $.65^{* *}$ & \\
\hline Performance avoidance & .08 & .07 & .13 & $.36^{* *}$ & $.49^{* *}$ \\
\hline Spain & INT & SOC & POP & Mastery & PAP-goals \\
\hline SOC & $.51^{* *}$ & & & & \\
\hline POP & $.72^{* *}$ & $.29 * *$ & & & \\
\hline Learning Goal & $.31^{* *}$ & $.32^{* *}$ & .18 & & \\
\hline Performance approach & $.24^{*}$ & .15 & .12 & $.24^{*}$ & \\
\hline Performance avoidance & .02 & -.05 & -.01 & .03 & $.31^{* *}$ \\
\hline
\end{tabular}

Note. $\left({ }^{*} p<.05 .{ }^{* *} p<.01\right.$; significance levels are given one-tailed for the approach motivations and two-tailed for the avoidance motivations).

In our second hypothesis we predicted that a performance avoidance orientation is not associated with the perception of intellectual abilities, social qualities and popularity of a new high-achieving classmate. However, our predication was only confirmed in 9 out of 15 cases. Unexpectedly, six correlations were, although weak, nevertheless significant and all had a positive sign. A closer examination of the associations between performance avoidance goals and the perceptions of high-achiever attributes revealed again substantial cross-national differences. All of the correlations were significant in Vietnam and, with the exception of the correlation between performance avoidance goals and social qualities, the correlations among the Korean students were also significant. In contrast, in line with our prediction none of the correlations in the Spanish-speaking countries of Peru and Spain were significant. A mixed result was found among the Australian students for whom the correlation with social qualities reached the set significance level $(p<0.05)$.

\section{Regression analyses}

To test if the motivational orientations predict perceptions of a new high-achieving student we conducted a series of multiple regression analyses within each participating country. Dependent variables were intellectual abilities, social qualities, and popularity of the new high-achieving student. Predictors in the stepwise multiple regression models were the three motivational orientations. Table 3 provides a summary of the results. 
Table 3. Results of the regression analyses.

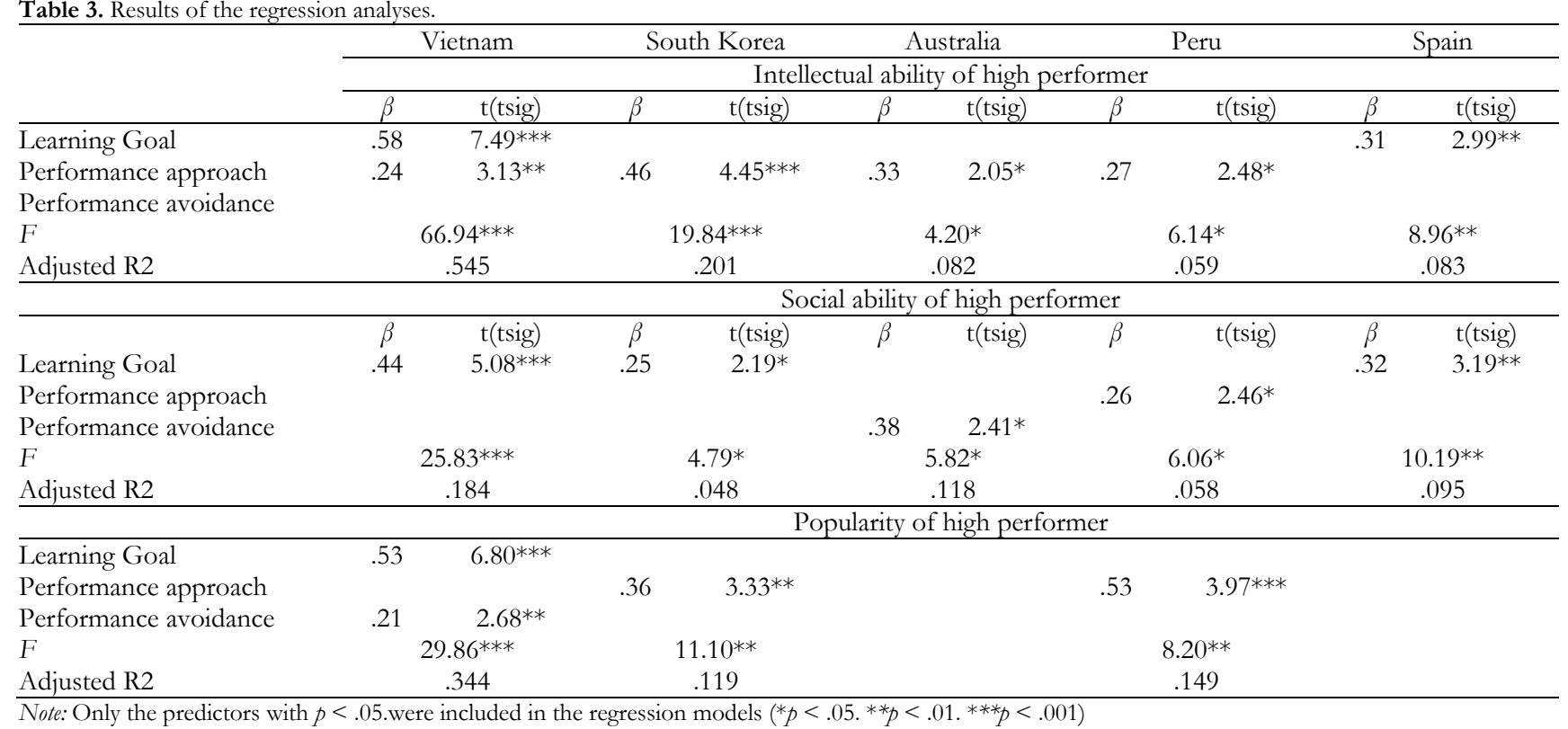

Intellectual abilities as an independent variable were predicted by a learning goal orientation in Vietnam and in Spain, while a performance approach orientation was a positive predictor in Vietnam, South Korea, Australia, and Peru. Thus, with regard to intellectual abilities Hypotheses 1 and 2 could, by and large, be confirmed.

The multiple regressions with social qualities of the highachieving student as a dependent variable revealed a significant effect of a learning goal orientation in Vietnam, South Korea, and Spain, while a performance approach orientation was a positive predictor in Peru. Unexpectedly in light of Hypothesis 2 the Australian students' performance avoidance orientation was also a predictor. However, in four of the five countries only, approach motivations predicted positive social attributes and only in one country the performance avoidance orientation, thus we regard Hypotheses 1 and 2 as, by and large, confirmed with the notable exception of the Australian sample.

It was only in Vietnam that the popularity of a highachieving student was predicted by a learning goal orientation. Though this result is in line with Hypothesis 1, unexpectedly in light of Hypothesis 2, a performance avoidance orientation was also a predictor. As predicted by Hypothesis 1 a performance approach motivation was a significant predictor in South Korea and in Peru. None of the motivational orientations predicted popularity of the new high-achieving student in either Australia or Spain. In summing up the results of these regression analyses with the popularity of the fictitious high-achieving student as the dependent variable, we found consistency with Hypothesis 1 in only three of the five countries relating to significant predictions through approach motivation, whereas there was consistency with Hypothesis 2 in four countries where performance avoidance motivation was not a predictor.

\section{Discussion}

The current study examined high-achieving students' perceptions of fictitious new classmates who had been the best student in his/her former school. Given the various social risks for high-achieving students and in particular that they might be stereotyped or labelled as nerds, geeks, etc. (e.g., Händel et al., 2013; Person, 2010: Peterson, 2009) one might wonder if they perceive a student of similar achievement with skepticism or if this student is rather seen as a potential model that confirms the adequacy of their own achievement behavior (Lee, 2002; Shin et al., 2016; Stopper, 2000). In response to this question, as a first result we can report: High achieving students in all countries participating in the study ascribe positive attributes to a new high-achieving student such as high intellectual abilities and social qualities. They also expect them to be popular among classmates. Thus, we can conclude that it is not perceived as a threat per se to be a high-achieving student as predominantly positive attributes are associated with high-achieving students.

We hypothesized that the perception of a high-achieving student might be mediated by the motivational orientations of the high-achieving students. However, we confined that assumption to the two approach goals - learning goal orientation and performance approach orientation (cf. Brendl et al., 2003; Ferguson \& Bargh, 2004). We expected no association between performance avoidance orientation and the perception of the new high-achieving classmate. By and large, the data were consistent with our first hypothesis across the countries. Most of the correlations indicated a positive relation between approach motivations and favorable perception of a high-achieving student. From an educational perspective these results suggest the possibility that the activation of approach goals in the classroom might fos- 
ter a positive perception of high-achieving classmates. Further studies should investigate if this applies also to average and low-achieving students. If this would be the case, increased positive attitudes towards high-achieving peers might also help average and low-achieving students to develop more positive attitudes towards learning and achievements.

Although the results showed, in accordance with our second hypothesis, that there was generally no statistically significant association between a performance avoidance orientation and the perception of a high-achieving student, there were some exceptions. Therefore, the second hypothesis had only limited support and a more cautious formulation of a hypothesis would seem to be in order. A more adequate formulation of the second hypothesis might be that a performance avoidance orientation has less influence on the perception of a high-achieving student than an approach orientation. This reformulation has two aspects: First, why does a performance avoidance motivation influence the perception of a high-achieving student at all and secondly, why is the influence less than the influence of the approach orientations? According to several authors avoidance oriented students' behaviors are presumed to be directed by an orientation toward negative achievement outcomes and are usually accompanied by negative affective states like fear of test failure and anticipating shame of an undesirable academic outcome (Dweck \& Leggett, 1988; Markman \& Brendl, 2000; Smith, 2004). Thus, according to these authors avoidance oriented students are indeed still oriented to achievement outcomes. This might explain the sporadic positive correlations with their perception of high-achieving students. However, for an avoidance oriented student, a highachieving student might be a less suitable role model than for an approach oriented student. At least this would be suggested by the devaluation assumption.

In conclusion we want to mention several limitations of our study. Although we found substantial between country differences, it should be pointed out that the samples were

\section{References}

Bagès, C. \& Martinot, D. (2011). What is the best model for girls and boys faced with a standardized mathematics evaluation situation: A hardworking role model or a gifted role model? British Journal of Social Psychology, 50(3), 536-543.

Baker; J.A., Bridger, R., \& Evans, K. (1998/2011). Models of underachievement among gifted preadolescents: The role of personal, family, and school factors. Gifted Child Quarterly, 42(1), 5-15. doi: 10.1177/001698629804200102

Behling, O., \& Law, K.S. (2000) Translating questionnaires and other research instruments: Problems and solutions. Thousand Oaks, CA: Sage.

Brendl, C. M., Markman, A. B., \& Messner, C. (2003). The Devaluation Effect: Activating a need devalues unrelated objects. Journal of Consumer Research, 29(4), 463-473. doi:10.1086/346243

Brophy, J. (2005). Goal Theorists Should Move on From Performance Goals. Educational Psychologist, 40(3), 167-176. doi:10.1207/s15326985ep4003_3

Dweck, C. S., \& Leggett, E. L. (1988). A social-cognitive approach to motivation and personality. Psychological Review, 95(2), 256-273. doi:10.1037/0033-295X.95.2.256 not intended to be representative of the country, but rather convenience samples. Thus, future studies need to investigate random country samples in order to make more substantiated claims about cross-national influences.

A second limitation of this study is that the internal consistency of the popularity scale, though still within the acceptable range, was rather low. The reason we were unable to find predictors of popularity in two countries might be in part due to the low reliability of this scale. Possibly these measurement problems of popularity may depend on the specific school environments. It is well-established that the attributes which constitute popularity in a school environment can vary greatly (Schwartz, Gorman, Nakamoto, \& McKay, 2006). Thus, in future research special care should be given to the development of a more reliable measurement of popularity and consideration of the potential differences in school contexts.

A third limitation is that the hypotheses we postulated assumed a direct impact of motivational orientations on the perception of a future high-achieving classmate. Therefore we did not specify any cultural related variable that might moderate the relationship. However, the results clearly falsified our culture-insensitive perspective. For example, the $\mathrm{R}^{2}$ for motivational orientations ranged from .55 for intellectual abilities as a dependent variable in Vietnam to insignificant predictions in Australia and in Spain for popularity as a dependent variable. Similarly the disparities within a country in terms of explained variances of the measured attributes of the fictitious new high-achieving classmate were also huge. These results lead us to the assumption that the effects were moderated by further factors that we failed to address in our study. However, this leads to the forth limitation we want to mention. Our data are cross-sectional and therefore no conclusions can be drawn about causality. In future, longitudinal and in particular experimental studies are needed in order to draw causal inferences and in particular to investigate possible moderators.

Elliot, A. J. (1999). Approach and avoidance motivation and achievement goals. Educational Psychologist, 34(3), 169-189. doi:10.1207/s15326985ep3403_3

Ferguson, M. J., \& Bargh, J. A. (2004). Liking is for doing: the effects of goal pursuit on automatic evaluation. Journal of Personality and Social Psychology, 87(5), 557-572. doi:10.1037/0022-3514.87.5.557

Fiedler, E.D., Lange, R. E., Winebrenner, S. (1993). In search of reality: Unraveling the myths about tracking, ability grouping, and the gifted. Roeper Review, 16, 4-7.

Händel, M., Duan, X., Sutherland, M. \& Ziegler, A. (2014). Successful in science and still popular: A pattern that is possible in China rather than in Germany or Russia. International Journal of Science Education. 36, 887907. DOI: $10.1080 / 09500693.2013 .830232$

Händel, M., Vialle, W., \& Ziegler, A. (2013). Student perceptions of high achieving classmates. High Ability Studies, 24, 99-114.

Harackiewicz, J. M., \& Elliot, A. J. (1993). Achievement goals and intrinsic motivation. Journal of Personality and Social Psychology, 65(5), 904-915. doi:10.1037/0022-3514.65.5.904

Heise, D. R. (2010). Surveying cultures: Discovering shared conceptions and sentiments. 
Hoboken, NJ: Wiley Interscience.

Hofstede, G. (2001). Cultures consequences (2nd ed.). Thousand Oaks, CA: Sage.

Lee, S.-Y. (2002). The effects of peers on the academic and creative talent development of a gifted adolescent male. Journal of Advanced Academics, 2002, 14(1), 19-29. doi: 10.4219/jsge-2002-387

Lockwood, P. \& Kunda, Z. (1997). Superstars and me: Predicting the impact of role models on the self. Journal of Personality and Social Psychology, 73(1), 91-103. http://dx.doi.org/10.1037/0022-3514.73.1.91

Markman, A. B., \& Brendl, C. M. (2000). The influence of goals on value and choice. Psychology of Learning and Motivation, 39, 97-128.

Neumeister, K. L. S., \& Finch, H. (2006). Perfectionism in High-Ability Students: Relational Precursors and Influences on Achievement Motivation. Giffed Child Quarterly, 50(3), 238-251. doi:10.1177/001698620605000304

Person, R. S. (2010). Experiences of intellectually gifted Students in an egalitarian and inclusive educational system: A survey study. Journal for the Education of the Gifted, 33(4), 536-569.

Peterson, J. S. (2009). Myth 17: Gifted and talented individuals do not have unique social and emotional needs. Gifted Child Quarterly, 53(3), 280-282. doi:10.1177/0016986209346946

Piechowski, M.M. (1997). Emotional giftedness: The measure of intrapersonal intelligence. In N. Colangelo and G.A. Davis (Eds.), Handbook of gifted education (2nd edition, pp. 366 - 381). Needham Heights: Allyn and Bacon.

Read, D., \& van Leeuwen, B. (1998). Predicting Hunger: The Effects of Appetite and Delay on Choice. Organizational Behavior and Human Decision Processes, 76(2), 189-205. doi:10.1006/obhd.1998.2803

Rossi, P. H., \& Nock, S. L. (Eds.) (1982). Measuring social judgments: The factorial survey approach. Beverly Hills, CA: Sage.

Salili, , F., Chiu, C., \& Lai, S. (2001). The influence of culture and context on students' motivational orientation and performance. In F Salili, C.Y. Chiu, \& Y.Y. Hong (Eds.), Student motivation: The culture and context of learning (pp. 221-248). New York: Plenum.

Schwartz, D., Gorman, A. H., Nakamoto, J., \& McKay, T. (2006). Popularity, social acceptance, and aggression in adolescent peer groups: links with academic performance and school attendance. Developmental Psychology, 42(6), 1116-1127. doi:10.1037/0012-1649.42.6.1116

Shin, J. E. L., Levy, S. R., \& London, B. (2016). Effects of role model exposure on STEM and non-STEM student engagement. Journal of Applied Social Psychology, Article first published online: 7 Jan 2016. DOI: 10.1111/jasp.12371

Smith, T.W. (2004). Developing and evaluating cross-national survey instruments. In: Presser S., Rothgeb, J., Couper, M., et al. (Eds.), Methods for testing and evaluating survey questionnaires (pp. 431-452). Hoboken, N.J.: John Wiley.

Smith, J. L. (2004). Understanding the Process of Stereotype Threat: A Review of Mediational Variables and New Performance Goal Directions. Educational Psychology Review, 16(3), 177-206. doi:10.1023/B:EDPR.0000034020.20317.89

Stopper, M. (Ed.) (2000). Meeting the social and emotional needs of gifted and talented children. London: NACE/ David Fulton Publishers.

Tao, V., \& Hong, Y.Y. (2000). A meaning system approach to Chinese students' achievement goals. Journal of Psychology in Chinese Societies, 1(2), 13-38.

Triandis, H. C. (1995). Individualism \& collectivism. Boulder: Westview Press.

Ziegler, A., Dresel, M., \& Stoeger, H. (2008). Addressees of performance goals. Journal of Educational Psychology, 100(3), 643-654. doi:10.1037/0022-0663.100.3.643

(Article received: 15-03-2016; revised: 21-03-2016; accepted: 06-04-2016) 